\title{
Arterial Oxygen Tension in Relation to Age in Hospital Subjects
}

\author{
OSCAR NEUFELD, M.D., F.C.C.P.*, JOSEF R. SMITH, M.D., F.A.C.P. $\dagger$ \\ and S. L. GOLDMAN, Ph.D. \\ Toledo, Ohio and Ann Arbor, Michigan
}

\begin{abstract}
One hundred and seventy-seven hospital patients whose ages ranged from 20 to 80 years were studied to determine whether or not there are any changes in arterial oxygen tension (during the breathing of room air) in relation to age. The findings indicated that there is an inverse correlation between age and arterial oxygen tension. This may be of great clinical significance since anoxemia has a pronounced effect on the central nervous system, the cardiopulmonary system, and many aspects of the preoperative and postoperative status of surgical patients. The present concept that normal arterial oxygen tension is $100 \mathrm{~mm} \mathrm{Hg}$, regardless of age, may have to be altered.
\end{abstract}

In previous studies on normal arterial oxygen tension, most of the subjects have been in the younger age groups. In the study presented here, arterial oxygen tension was determined in hospital subjects of a broad age spectrum; one third of them were in the 61-80 age group.

Physiology textbooks state that normal arterial oxygen tension is $100 \mathrm{~mm} \mathrm{Hg}$ when the subject is breathing room air. Lambertson (1), however, gives a value of $95 \mathrm{~mm} \mathrm{Hg}$. Raine and Bishop (2) have emphasized two modifying factors, i. e., age and the position of the subject. In subjects younger than 40 , the mean arterial oxygen tension $\left(\mathrm{PaO}_{2}\right)$ was $97.6 \mathrm{~mm}$ $\mathrm{Hg}$ in the sitting position and $95.3 \mathrm{~mm}$ in the supine position; in those older than 40 , the $\mathrm{PaO}_{2}$ was $90.0 \mathrm{~mm}$ in the sitting position and $88.2 \mathrm{~mm}$ while prone. Stephen and Talton (3) found that the arterial oxygen tension in 14 patients lying supine in the ward awaiting elective surgery averaged $80.4 \mathrm{~mm} \mathrm{Hg}$. The values ranged between $100 \mathrm{~mm}$ in a 28 -year-old

* Director, Pulmonary Function Laboratory, Mercy Hospital; Clinical Associate in Medicine, Medical College of Ohio, Toledo, Ohio.

Address: Oscar Neufeld, M. D., Professional Building (Suite 201), 1838 Parkwood Avenue, Toledo, Ohio 43624 .

$\dagger$ Professor of Internal Medicine, University of Michigan, Ann Arbor, Michigan.

$\ddagger$ Assistant Professor of Biology, University of Toledo, Toledo, Ohio. patient and $57.5 \mathrm{~mm}$ in a 68 -year-old patient. The average age for the group was 47.3 years, with a range of $28-68$ years.

In the selection of patients for our study, emphasis was placed on covering: 1) a wide range of age, and 2) a representative crosssection of the population, including smokers.

\section{MATERIAL AND METHODS}

Arterial oxygen tension $\left(\mathrm{PaO}_{2}\right)$ was determined in 177 subjects (93 males and 84 females) whose ages ranged between 20 and 80 years. Carefully excluded from the study were postoperative patients, patients in the coronary-care unit, and those in a state of respiratory acidosis or alkalosis. All the investigations were made while the subjects were breathing room air.

Blood samples were drawn in a heparinized tube and analyzed immediately for $\mathrm{PO}_{2}, \mathrm{PCO}_{2}$ and $\mathrm{pH}$. Measurements of arterial oxygen tension $\left(\mathrm{PaO}_{2}\right)$ were made with the use of a Clark polyethylene-covered electrode, and those of oxygen saturation $\left(\mathrm{SaO}_{2}\right)$ with the aid of the Henderson-Hasselbalch equation. $\mathrm{PCO}_{2}$ was determined according to the SiggaardAndersen nomogram. The $\mathrm{pH}$ was measured immediately after blood collection, with use of a gas electrode. Corrections were made for body temperature. 
Measurements of alveolar carbon dioxide tension $\left(\mathrm{PACO}_{2}\right)$ were made with a $\mathrm{CO}_{2}$ meter, on end-expired and/or rebreathing gas samples. The physiological dead space (VOml) was calculated according to the Bohr formula; $\mathrm{PaCO}_{2}$ was substituted for $\mathrm{PACO}_{2}$. Ventilatory measurements were made with a 13.5-liter Collins spirometer (drum speed 2.8 and 16 $\mathrm{mm} / \mathrm{second}$ ). The residual volume, total lung capacity, and the ratio of residual volume to total lung capacity were determined with a closed-circuit Cambridge helium apparatus. The ventilatory studies were a part of a long-term investigation.

\section{RESULTS}

For the total of 177 single $\mathrm{PaCO}_{2}$ determinations, the grand mean value was $84.8 \mathrm{~mm} \mathrm{Hg}$. As shown in Table 1 , the patients were classified according to consecutive age decades ranging from 20-30 to 71-80. Each decade was represented by about 30 subjects. The $\mathrm{PaO}_{2}$ values ranged from a high of $89.6 \mathrm{~mm} \mathrm{Hg}$ in the youngest group (20-30 years) to a low of $82.8 \mathrm{~mm}$ in the oldest group (71-80 years). There was a marked similarity of $\mathrm{PaO}_{2}$ values in the intermediate groups, with a mean of about $84 \mathrm{~mm} \mathrm{Hg}$.

To determine whether or not a causal relationship existed between arterial oxygen tension and age, 3 regression equations were calculated. The first of these (Fig. 1) tests the relationship between $\mathrm{PaCO}_{2}$ and age in the 93 males and is described by the equation $\mathrm{PaCO}_{2}=88.36-0.087$ (age) with a standard deviation of $10.8 \mathrm{~mm} \mathrm{Hg}$. Statistical significance was not indicated. Figure 2 shows the relationship between $\mathrm{PaCO}_{2}$ and age in the 84 females and is defined by the equation $\mathrm{PaCO}_{2}=92.39-0.137$ (age) with a standard deviation of $10 \mathrm{~mm} \mathrm{Hg}$. Since the slope of this line is statistically different from zero, signifi-

TABLE 1

$\mathrm{PaO}_{2}$ Mean Values $\pm S D$ for 6 Consecutive Age Groups (Total, 177 Patients)

\begin{tabular}{c|c|c|c}
\hline Age Group & $\begin{array}{c}\text { No. of } \\
\text { Obs. }\end{array}$ & $\begin{array}{c}\mathrm{PaO}_{2} \\
\mathrm{Mean} \\
(\mathrm{mm} \mathrm{Hg})\end{array}$ & $\begin{array}{c}\text { Standard } \\
\text { Deviation } \\
(\mathrm{mm} \mathrm{Hg})\end{array}$ \\
\hline $20-30$ & 29 & 89.6 & 10.1 \\
$31-40$ & 30 & 84.0 & 13.0 \\
$41-50$ & 30 & 84.7 & 8.3 \\
$51-60$ & 29 & 83.6 & 9.8 \\
$61-70$ & 29 & 84.1 & 10.8 \\
$71-80$ & 30 & 82.8 & 11.7 \\
\hline
\end{tabular}

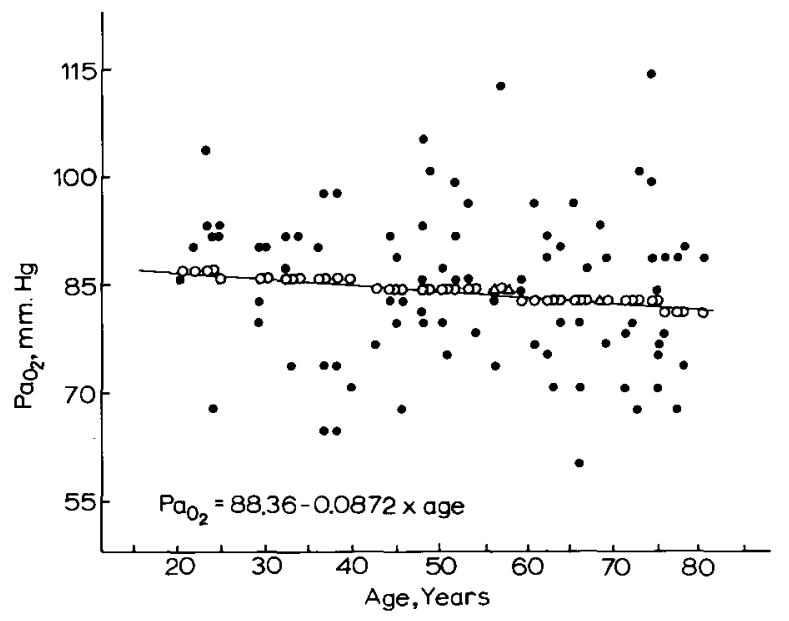

Fig. 1. Arterial oxygen tension in relation to age in 93 adult male subjects. The black dots represent single estimations of arterial oxygen tension; the circles represent predicted values; and the triangles represent the points at which predicted and experimental values coincide. The regression line and the formula from which it was derived are shown.

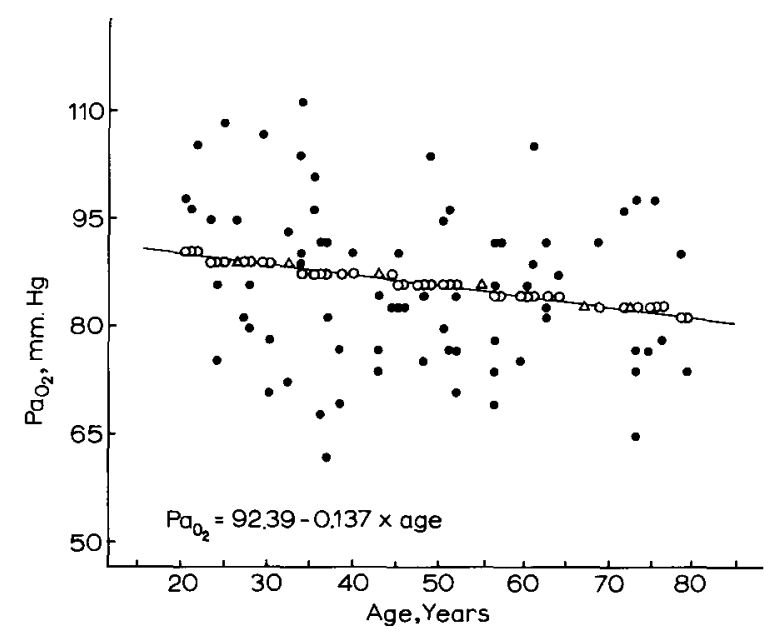

Fig. 2. Arterial oxygen tension in relation to age in 84 adult female subjects. The black dots represent single estimations of arterial oxygen; the circles represent predicted values; and the triangles represent the points at which predicted and experimental values coincide. The regression line and the formula from which it was derived are shown.

cance is noted between age and arterial oxygen tension among the females. Figure 3 shows this relationship in the total sample of 177 patients and is described by the equation $\mathrm{PaCO}_{2}=90.74-0.119$ (age) with a standard deviation of $10.7 \mathrm{~mm} \mathrm{Hg}$. Here also the slope of the line is significantly different from zero, indicating a dependency of age upon the level of arterial oxygen tension. In addition, the failure to demonstrate a significant inverse correlation between age and $\mathrm{PaO}_{2}$ in males 


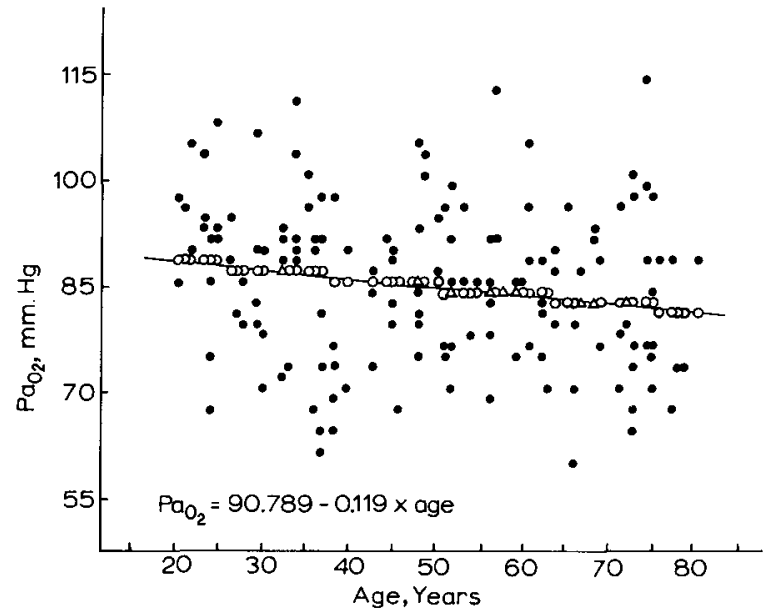

Fig. 3. Arterial oxygen tension in relation to age in 177 adults. The black dots represent single estimations of arterial oxygen tension; the circles represent predicted values; and the triangles represent the points at which predicted and experimental values coincide. The regression line and formula from which it was derived are shown.

(Fig. 1), while demonstrating it in females (Fig. 2 ), indicates an innate physiological difference between the sexes, as yet unexplained.

When the study subjects were pooled without regard to sex, the level of arterial oxygen tension was dependent upon age. Table 2 shows the differences between the $\mathrm{PaO}_{2}$ mean for the 71-80 age group and the $\mathrm{PaO}_{2}$ means for the five younger age groups. The mean $\mathrm{PaO}_{2}$ value for the 71-80 decade was significantly different only from that for the 20-30 decade.

When reciprocal tests were made, i. e., when the mean $\mathrm{PaO}_{2}$ value for decade 20-30 was compared to all the others, a significance at $5 \%$ was demonstrated from decades 41-50 through 71-80 (Table 3 ). The data strongly suggest that some physiological alteration which affects arterial oxygen tension occurs at or soon after age 40. Furthermore, this change remains relatively stable up through the eighth decade. Thus, with respect to this phenomenon, and when sex is excluded as a variable, a population may be viewed as consisting of pre- 40 and post-40 subgroups.

The foregoing observations made it necessary to determine whether or not the means we compared were from the same populations. For each $t$ test, the corresponding $F$ value was calculated. In no case was significance noted. Thus the variances were not different and the mean values did come from the same popula- tion. Tables 4 and 5 give the results of these analyses.

\section{DISCUSSION}

The average values and range for arterial oxygen tension reported here are in agreement with most of those reported in extensive published studies (Table 6). The lower values for the older age groups and the magnitude of our standard deviation can be explained by the inclusion of a large sample of hospital inpatients, in contrast to the carefully selected clinical material in the other studies.

The causes for the decrease in $\mathrm{PO}_{2}$ in the elderly can be attributed to: 1) venoarterial shunt, 2) diffusion gradient, and 3) unequal distribution. With advancing age, lung volumes decrease $(12,17)$, lung compliance diminishes (13), the distribution of ventilation becomes less even (14), the diffusing capacity of the lung decreases $(15,16)$, the ratio of physiological dead space to tidal volume is slightly greater

TABLE 2

Differences between the Mean $\mathrm{PaO}_{2}$ for the 71-80 Age Group and the Means for the Younger Age Groups

\begin{tabular}{cccccc}
\hline & \multicolumn{5}{c}{ Age Groups } \\
\cline { 2 - 6 } & $20-30$ & $31-40$ & $41-50$ & $51-60$ & $61-70$ \\
\hline$t$ value & $2.50 *$ & 0.40 & 0.78 & 0.30 & 0.48 \\
\hline
\end{tabular}

* Significance at $5 \%$.

TABLE 3

Differences between the Mean $\mathrm{PaO}_{2}$ for the 20-30 Age Group and the Mean for Each Successive Age Group

\begin{tabular}{rrrrrr}
\hline \multicolumn{6}{c}{ Age Groups } \\
\cline { 2 - 6 } & $31-40$ & $41-50$ & $51-60$ & $61-70$ & $71-80$ \\
\hline$t$ value & 1.8 & $2.3^{*}$ & $2.48^{*}$ & $2.04^{*}$ & $2.50^{*}$ \\
\hline
\end{tabular}

* Significance at $5 \%$.

TABLE 4

Differences between the Variance of $\mathrm{PaO}_{2}$ for the 71-80 Age Group and the Variances for the Younger Age Groups

\begin{tabular}{cccccc}
\hline & \multicolumn{5}{c}{ Age Groups } \\
\cline { 2 - 6 } & $20-30$ & $31-40$ & $41-50$ & $51-60$ & $61-70$ \\
\hline F value & 1.4 & 1.2 & 2.0 & 1.4 & 1.2 \\
\hline
\end{tabular}

No significances at $5 \%$ were noted. 
during exercise (17), and the anatomical dead space is larger (18). The increase in alveolar dead space was demonstrated by Riley et al. (19), who attributed it to underperfusion of pulmonary capillaries in the upper zones of the lungs. This idea was supported by the findings of studies in which bronchospirometry and

TABLE 5

Difference between the Variance of $\mathrm{PaO}$, for the 20-30 Age Group and the Variance for Each Successive

\begin{tabular}{cccccc}
\multicolumn{6}{c}{ Age Group } \\
\hline & \multicolumn{6}{c}{ Age Groups } \\
\hline & $31-40$ & $41-50$ & $51-60$ & $61-70$ & $71-80$ \\
\hline F value & 1.7 & 1.5 & 1.1 & 1.2 & 1.4 \\
\hline
\end{tabular}

No significances at $5 \%$ were noted. radioactive gases were used $(20,21)$. Several investigators $(15,16)$ concluded that, even when diffusing capacity is severely reduced by disease or with age, the reduction cannot account for a measurable part of the increase in alveolar-arterial oxygen difference because the end-capillary gradient does not exceed $1 \mathrm{~mm}$ $\mathrm{Hg}$.

The contribution of the anatomical shunt component explains only a small part of the observed increase in alveolar-arterial oxygen difference (22). Mellemgaard (10) concluded that, of the normal alveolar-arterial oxygen difference, only a small fraction is caused by the right-to-left "anatomical" shunt in the lung and less than half is caused by the bronchial and Thebesian vein drainage to the left side of

TABLE 6

Summary of Measurements of $\mathrm{PaO}_{2}$ by Previous Workers

\begin{tabular}{|c|c|c|c|c|c|}
\hline \multirow[b]{2}{*}{ Authors } & \multirow{2}{*}{$\begin{array}{l}\text { No. of } \\
\text { Subjects }\end{array}$} & \multirow{2}{*}{$\begin{array}{l}\text { Age } \\
\text { Range } \\
\text { (yrs.) }\end{array}$} & \multicolumn{2}{|c|}{$\mathrm{PaO}_{2}(\mathrm{~mm} \mathrm{Hg})$} & \multirow[b]{2}{*}{ Methods of $\mathrm{PaO}_{2}$} \\
\hline & & & mean & range or $\mathrm{SD}$ & \\
\hline Bartels and Rodewald (4) & 59 & $22-42$ & 92.9 & \pm 5.6 & Dropping mercury electrode \\
\hline Filley et al. (5) & $\begin{array}{r}15 \\
4\end{array}$ & $\begin{array}{l}23-35 \\
52-60\end{array}$ & $\begin{array}{l}86.9 \\
78.2\end{array}$ & $\begin{array}{l}81-96 \\
70-89\end{array}$ & Bubble equilibration \\
\hline Loew and Thews (6) & $\begin{array}{r}117 \\
79 \\
99 \\
66 \\
29\end{array}$ & $\begin{array}{c}18-30 \\
31-40 \\
41-40 \\
51-60 \\
>60\end{array}$ & $\begin{array}{l}93.7 \\
84.5 \\
80.1 \\
76.9 \\
70.0\end{array}$ & $\begin{array}{l} \pm 6.6 \\
\pm 8.7 \\
\pm 7.6 \\
\pm 5.6 \\
\end{array}$ & $\begin{array}{l}\text { Teflon-covered } \\
\text { Pt-micro electrode }\end{array}$ \\
\hline Raine and Bishop (2) & $\begin{array}{r}14 * \\
32 \dagger \\
7 * \\
17 \dagger\end{array}$ & $\begin{array}{l}<40 \\
<40 \\
>40 \\
>40\end{array}$ & $\begin{array}{l}95.3 \\
97.6 \\
88.2 \\
90.9\end{array}$ & $\begin{array}{l} \pm 6.9 \\
\pm 8.4 \\
\pm 9.8 \\
\pm 6.9\end{array}$ & $\begin{array}{l}\text { Polyethylene-covered } \\
\text { Pt-electrode }\end{array}$ \\
\hline Ulmer and Reichel (7) & $\begin{array}{l}28 \\
16 \\
18 \\
16 \\
10\end{array}$ & $\begin{array}{c}<30 \\
30-40 \\
40-50 \\
50-60 \\
>60\end{array}$ & $\begin{array}{l}90.96 \\
88.96 \\
86.56 \\
80.75 \\
79.70\end{array}$ & $\begin{array}{r} \pm 8.30 \\
+11.09 \\
+9.10 \\
+17.20 \\
\pm 8.50\end{array}$ & Teflon-covered Pt-electrode \\
\hline Marshall and Miller (8) & $\begin{array}{r}20 \\
10 \\
10 \\
10 \\
6\end{array}$ & $\begin{array}{l}21-30 \\
31-40 \\
41-50 \\
51-60 \\
61-70\end{array}$ & $\begin{array}{l}96.0 \\
94.0 \\
88.5 \\
86.7 \\
85.9\end{array}$ & $\begin{array}{l} \pm 0.90(\mathrm{SE}) \\
\pm 1.80(\mathrm{SE}) \\
\pm 1.20(\mathrm{SE}) \\
\pm 1.50(\mathrm{SE}) \\
\pm 2.70(\mathrm{SE})\end{array}$ & Teflon-covered Pt-electrode \\
\hline Conway et al. (9) & $\begin{array}{r}7 \\
22 \\
30 \\
11\end{array}$ & $\begin{array}{l}<30 \\
30-45 \\
46-60 \\
>60\end{array}$ & $\begin{array}{l}96.8 \\
93.7 \\
91.3 \\
86.0\end{array}$ & $\begin{array}{r} \pm 2.7 \\
\pm 7.2 \\
\pm 8.5 \\
\pm 11.7\end{array}$ & $\begin{array}{l}\text { Stirred Bishop cuvette or } \\
\text { unstirred Beckman } \\
\text { electrode }\end{array}$ \\
\hline Mellemgaard (10) & $\begin{array}{l}12 \\
16 \\
12 \\
16 \\
12 \\
12\end{array}$ & $\begin{array}{l}15-20 \\
21-30 \\
31-40 \\
41-50 \\
51-60 \\
61-75\end{array}$ & $\begin{array}{l}98.9 \\
97.8 \\
93.1 \\
92.6 \\
87.9 \\
86.7\end{array}$ & $\begin{array}{l} \pm 5.1 \\
\pm 6.6 \\
\pm 5.6 \\
\pm 9.1 \\
\pm 6.9 \\
\pm 8.3\end{array}$ & Dropping mercury electrode \\
\hline Sorbini et al. (11) & $\begin{array}{l}38 \\
30 \\
30 \\
30 \\
24\end{array}$ & $\begin{array}{c}<30 \\
31-40 \\
41-50 \\
51-60 \\
>60\end{array}$ & $\begin{array}{l}94.2 \\
87.2 \\
83.9 \\
81.2 \\
74.3\end{array}$ & $\begin{array}{l}1.8 \\
2.0 \\
2.4 \\
2.9 \\
2.1\end{array}$ & Teflon-covered Pt-electrode \\
\hline
\end{tabular}

* Supine.

+ Sitting. 
the heart. The remaining part, which increases with age, apparently is caused by inequalities of the ventilation-perfusion ratio in the lungs. Joos et al. (23) compared the values in 50 healthy subjects of the 70-80 age group with the ideal values and found oxygen saturation to be at the lower limit of normal during rest followed by a slight increase during moderate exercise. Their interpretation was that these changes are associated with inadequate distribution.

Perhaps the most widely accepted explanation for the decrease in arterial oxygen tension with age is that an alteration occurs in the ventilation-perfusion ratio between gas and perfusing blood in the lungs $(24,25)$. The question of whether ordinary slow breathing versus deep breathing is related to variability in ventilation of the lungs has been under considerable debate. Haldane and Priestley (26) believed that the different parts of the lung are unequally ventilated and that this inequality depends upon the depth and the rate of breathing. Krogh and Lindhard (27) found that these differences were small with ordinary breathing but large with deep breathing. Dill et al. (28) provided excellent evidence of the incomplete mixing of lung gases in old men. They held that unequal ventilation of the lobes of the lung is an important phenomenon during quiet breathing in some old men. Sonne (29) presented experimental evidence for variability in the different lobes of the lung, and Sorbini et al. (11) concluded that increased inequality in the $V / D$ ratio probably was the cause of the decline of arterial oxygen tension with increasing age.

Both an increase in alveolar-arterial oxygen tension with age $(7,10,22,30)$ and an inverse correlation between age and arterial oxygen tension (7-10) have been demonstrated. It would be reasonable to assume that: 1 ) the small differences in arterial oxygen tension between patients in the seated and in the supine positions are of limited significance; 2) the differences in standard deviation noted in the various large studies reported in the literature are likely based on the selection of subjects and possibly on the methods used; and 3 ) age is a significant factor in lowering arterial oxygen tension. Clinically, these findings may be related to the effects of anoxemia on the central nervous system and the cardiopulmonary system, in preoperative and postoperative conditions, in traveling, or in living at high altitudes. Our studies show that the variation of arterial oxygen tension with age is such that the definition of normal values without regard to age is not justified. In fact, there is a marked inverse relationship between arterial oxygen tension and age. The present value of $100 \mathrm{mg} \mathrm{Hg}$ for normal arterial oxygen tension may have to be revised.

\section{Acknowledgments}

Our thanks to Mr. Ronald S. Neufeld, B.S., for assistance with the statistical calculations and tables, and to Mrs. B. Carstenson for assistance with the laboratory determinations.

\section{REFERENCES}

1. Lambertson, C. J.: Gas exchanges of the atmosphere, lungs and blood; Chapter 36 in Medical Physiology, ed. by P. Bard. St. Louis, C. V. Mosby, 1961.

2. Raine, J. M., and Bishop, J. M.: A-a difference in $\mathrm{O}_{2}$ tension and physiological dead space in normal man, J. Appl. Physiol. 18: 284, 1963.

3. Stephen, C. R., and Talton, I.: Immediate postoperative care with particular reference to bloodgas studies, Canad. Anaesth. Soc. J. 11: 586-597, 1964

4. Bartels, H., and Rodewald, G.: Arterial oxygen tension, alveolar-arterial oxygen pressure difference and further respiratory-physiologic data on healthy males, Arch. Ges. Physiol. 256: 113-135, 1952 .

5. Filley, G. F.; Gregoire, F., and Wright, G. W.: Alveolar and arterial oxygen tensions and significance of alveolar-arterial oxygen tension difference in normal men, J. Clin. Invest. 33: 517-529, 1954.

6. Loew, P. G., and Thews, G.: The dependency of the arterial oxygen pressure on age in the working population, Klin. Wchnschr. 40: 1093-1098, 1962.

7. Ulmer, W. T., and Reichel, G.: Studies on the correlations between age and alveolar and arterial oxygen and carbon dioxide pressure, Klin. Wchnschr. 41: 1-6, 1963 .

8. Marshall, B. E., and Miller, R. A.: Some factors influencing post-operative hypoxaemia, Anaesthesia $20: 408-428,1965$.

9. Conway, C. M.; Payne, J. P., and Tomlin, P. J.: Arterial oxygen tensions of patients awaiting surgery, Brit. J. Anaesth. 37: 405-408, 1965.

10. Mellemgaard, K.: The alveolar-arterial oxygen difference: its size and components in normal man, Acta Physiol. Scandinav. 67: 10-20, 1966.

11. Sorbini, C. A., et al.: Arterial oxygen tension in relation to age in healthy subjects, Respiration 25 : 3,1968 .

12. Greifenstein, F. E., et al.: Pulmonary function studies in healthy men and women 50 years and older, J. Appl. Physiol. 4: 641-648, 1952.

13. Pierce, J. A., and Ebert, R. V.: The elastic properties of the lungs in the aged, J. Lab. \& Clin. Med. 51: 63-71, 1958.

14. Bates, D. V., and Christie, R. V.: Intrapulmonary mixing of helium in health and in emphysema, Clin. Sc. 9: 17-29, 1950.

15. Burrows, B., et al.: Clinical usefulness of the single-breath pulmonary diffusing capacity test, Am. Rev. Resp. Dis. 84: 789-806, 1961. 
16. Cohn, J. E., et al.: Maximal diffusing capacity of the lung in normal male subjects of different ages, J. Appl. Physiol. 6: 588-597, 1954.

17. Fowler, W. S.: Lung function studies; postural changes in respiratory dead space and functional residual capacity, J. Clin. Invest. 29: 1437-1438, 1950 .

18. Wilson, R. H., et al.: An evaluation of the single-breath technique for measuring anatomic respiratory dead space with a nitrogen meter, Am. J. Med. Sc. 232: 67, 1956.

19. Riley, R. L., et al.: Maximal diffusing capacity of the lungs, J. Appl. Physiol. 6: 573-587, 1954

20. Dock, W.: Apical localization of phthisis; its significance in treatment by prolonged rest in bed, Am. Rev. Tuberc. 53: 297-305, 1946.

21. Mattson, S. B., and Carlens, E.: Lobar ventilation and oxygen uptake in man, J. Thoracic Surg. 30: $676-682,1955$

22. Bishop, J. M., and Cole, R. B.: The effects of inspired oxygen concentration, age and body position upon the alveolar-arterial oxygen tension difference $(\mathrm{A}-\mathrm{aD})$ and physiological dead space, $J$. Physiol. (Lond.) 162: 60-61, 1962.
23. Joos, H.; Rossier, P. H., and Buhlman, A.: Die Lungenfunktion im Alter, Schweiz. Med. Wchnschr. 87: 806, 1957.

24. Conway, C. M., and Payne, J. P.: Post-operative hypoxemia and oxygen therapy, Brit. Med. J. $1: 844,1963$.

25. West, J. B.: Blood flow, ventilation, and gas exchange in the lung, Lancet $2: 1055,1963$.

26. Haldane, J. S., and Priestley, J. G.: Respiration. London, Oxford U. Press, 1935.

27. Krogh, A., and Lindhard, J.: The volume of the dead space in breathing and the mixture of gases in the lungs of man, J. Physiol. 51: 59, 1917.

28. Dill, D. B.; Graybiel, A.; Hurtado, A., and Taquini, A. C.: Gaseous exchange in the lungs in old age, J. Am. Geriatries Soc. 11: 1063-1076, 1963.

29. Sonne, F.: Inequality of ventilation of different parts of lung as source of error in respiratoryphysiological experiments, Scandinav. Arch. Physiol. 75: 127-138, 1936.

30. Terman, J. W., and Newton, J. L.: Changes in alveolar and arterial gas tensions as related to altitude and age, J. Appl. Physiol. 19: 21-24, 1964. 